\title{
Effect of heating rate on densification and magnetic properties of MnZn ferrites sintered by multiphysical fields coupling methodology
}

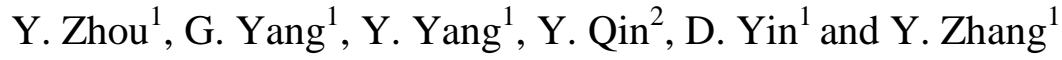 \\ 1School of Manufacturing Science and Engineering, Sichuan University, Chengdu, Sichuan 610065, China \\ 2 Centre for Precision Manufacturing, Department of DMEM, University of Strathclyde, James Weir Building, \\ 75 Montrose Street, Glasgow G1 1XJ, UK
}

\begin{abstract}
This work has provided a novel idea of fabricating MnZn bulk ferrite materials. MnZn ferrite powders with a composition of $\mathrm{Zn}_{0.8} \mathrm{Mn}_{0.2} \mathrm{Fe}_{2} \mathrm{O}_{4}$ (wt-\%) were sintered under coupled multiphysical fields applied by Gleeble-1500D thermal simulation instrument. Cylindrical bulk ferrites with a diameter of $2.5 \mathrm{~mm}$ and a height of $2.5 \mathrm{~mm}$ were prepared, and the effect of heating rate on densification and magnetic properties of MnZn ferrites was studied. The results show that the densification and magnetic properties of $\mathrm{MnZn}$ ferrite were directly affected by the heating rates. A relative density of up to $98.5 \%$ was achieved when the heating rate of $100^{\circ} \mathrm{C} \mathrm{s}^{-1}$ was used. Such magnetic properties as maximum energy product and remanence of MnZn ferrite sintered under coupled multiphysical fields are improved when compared to samples produced by conventional sintering. In particular, a $204.39 \%$ increase in maximum energy product is obtained. Finally, the densification mechanisms of multiphysical fields sintering method are discussed.
\end{abstract}

Keywords: Densification, Magnetic properties, MnZn ferrite, Fields coupling methodology, High frequency wave

\section{Introduction}

MnZn ferrites are important soft magnetic materials, owing to their high saturation magnetic induction $\mathrm{B}_{\mathrm{s}}$, relatively high Curie temperature $\mathrm{T}_{\mathrm{c}}$, low power losses $\mathrm{P}_{\mathrm{cv}}$ and high initial permeability $\mathrm{m}_{\mathrm{i}}$ within broad temperature scope. They are widely applied as core materials in electronic applications, relating to as sensors, lighting transformer, power supply filter and recording heads. ${ }^{1}$ It is well known that the properties of $\mathrm{MnZn}$ ferrite could be greatly influenced by the synthesis method, the forming process and sintering parameters. ${ }^{2}$ For example, the powder metallurgy process, as the conventional and commonly used method, requires high sintering temperature and long sintering time in a controlled atmosphere. ${ }^{3,4}$ However, the poor reproducibility and cost of long holding time are the major shortcomings of conventional sintering method. With the aim to seek the fast and low temperature preparation of MnZn ferrites, great advances have been made in recent decades. ${ }^{5,6}$ For instances, Sun et al. ${ }^{7}$ successfully fabricated dense $(\mathrm{NiZn}) / \mathrm{Fe}_{2} \mathrm{O}_{4}$ with uniform and fine grain size utilising electric field sintering technology, and Zhang et al. ${ }^{8}$ produced MnZn ferrite materials with spinel structure using spark plasma sintering (SPS). The initial permeability of MnZn ferrite materials sintered with SPS is 103, and the relative density is $99.5 \%$. However, the segregation of MnZn ferrite composition during SPS process seriously limited the further enhancement of magnetic properties of $\mathrm{MnZn}$ ferrite. Recently, Yang et al. ${ }^{9}$ used multiphysical fields coupling method to prepare $\mathrm{NbFeB}$ magnetic materials, and significant improvement in magnetic properties was achieved. ${ }^{10,11}$ 
In comparison with SPS, a much higher heating rate can be realised in multiphysical fields coupling method; it is expected that sintering process in this way can be finished in a lower sintering temperature and a shorter sintering time. Therefore, in this work, multiphysical fields coupling method was used to fabricate the MnZn ferrites, and their magnetic properties were characterised. Moreover, the effect of heating rate on densification and magnetic properties of MnZn ferrites was investigated to discuss the sintering mechanisms.

\section{Experimental}

The raw material consists of $\mathrm{FeO}_{2}, \mathrm{MnO}_{2}, \mathrm{ZnO}$ and some impurities. The mass ratios of the sample are $\mathrm{MnO}_{2} 50.25, \mathrm{FeO}_{2} 50.60$ and $\mathrm{ZnO} 50.15$, impurities include yttrium oxide, niobium oxide and nickel oxide; their mass fraction is about $0.05 \%$. MnZn ferrite powders were first synthesised by the sol-gel autocombustion method and then ball milled $3 \mathrm{~h}^{12}$ Afterwards, the powders were loaded into a small die with inner diameter of $2.5 \mathrm{~mm}$. The die was then sandwiched between two pads that were in close contact with the two electrodes of the Gleeble thermal simulation instrument. Thermocouple wires were soldered onto the surface of the die to measure the temperature. It should be noted that the nominal temperature, measured by the electrodes, is not the true temperature of the sample and usually slightly lower than the true temperature of the sample 13 .

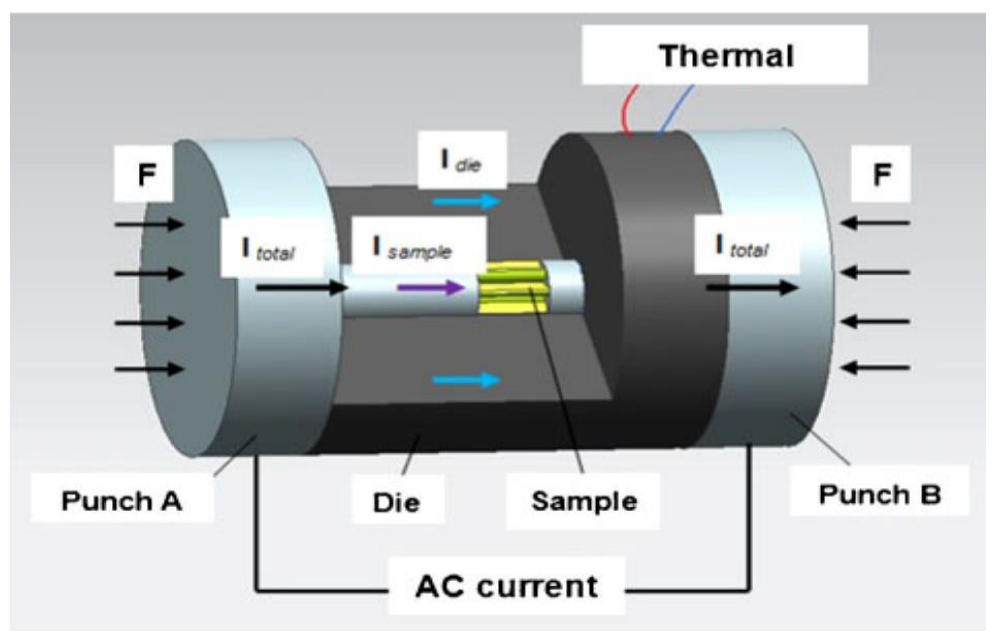

Fig. 1 Schematic diagram of Gleeble-1500D equipment

The experiments were carried out using the Gleeble1500D thermal simulation instrument (Dynamic System Inc., USA). The schematic map of the equipment is shown in Fig. 1. The required experimental heating conditions were preprogrammed into the computer control system. Various heating rates of 50,80 and $100^{\circ} \mathrm{C} \mathrm{s}^{-1}$ were adopted in the experiments. The chamber was first evacuated to $<10^{-3} \mathrm{~Pa}$ before the sintering process started. Afterwards, $\mathrm{MnZn}$ ferrite powders were rapidly heated to $900^{\circ} \mathrm{C}$ at pre-set heating rates. A pressure of $0.35 \mathrm{kN}$ was applied to the powders through the punches when the heating process started. After a 4 min thermal retardation time, the Gleeble-1500D thermal simulation instrument was turned off, and the sample was cooled down to room temperature in a vacuum atmosphere.

The density of sintered MnZn ferrite was measured with Archimedes' principle. X-ray diffraction and scanning electron microscope (SEM) were used to examine the phase structures and the microstructures of the sample. Magnetic properties were determined by a vibration sample magnetometer. 


\section{Results and discussion}

\section{Microstructural evolution}

The X-ray diffraction patterns of sintered MnZn ferrites before and after sintering are presented in Fig. 2. It is clearly shown that the powders before sintering consist of $\mathrm{FeO}_{2}, \mathrm{MnO}_{2}, \mathrm{ZnO}$ and $\mathrm{Zn}_{0.8} \mathrm{Mn}_{0.2} \mathrm{Fe}_{2} \mathrm{O}_{4}$, but specimens almost consist of $\mathrm{Zn}_{0.8} \mathrm{Mn}_{0.2} \mathrm{Fe}_{2} \mathrm{O}_{4}$ after sintering, implying that chemical reaction occurs in the sample during sintering.

Figure 3 shows the microstructures of the cross-section of $\mathrm{Zn}_{0.8} \mathrm{Mn}_{0.2} \mathrm{Fe}_{2} \mathrm{O}_{4}$ (wt- $\%$ ) specimens sintered at $900^{\circ} \mathrm{C}$ with different heating rates ranging from 50 to $100^{\circ} \mathrm{C} \mathrm{s}^{-1}$. It can be found that solid phase reaction of $\mathrm{MnZn}$ ferrite materials is not completely accomplished in the sample because of the dark areas, which indicates the raw materials and represents the incompletely sintered area. When the preset heating rate is $50^{\circ} \mathrm{C} \mathrm{s}^{-1}$, many raw particles remain in the compact, and welding spots between grains are not formed. With the heating rate to $80^{\circ} \mathrm{C} \mathrm{s}^{-1}$, less raw particles could be found in the compacts, resulting in the relatively denser compacts.

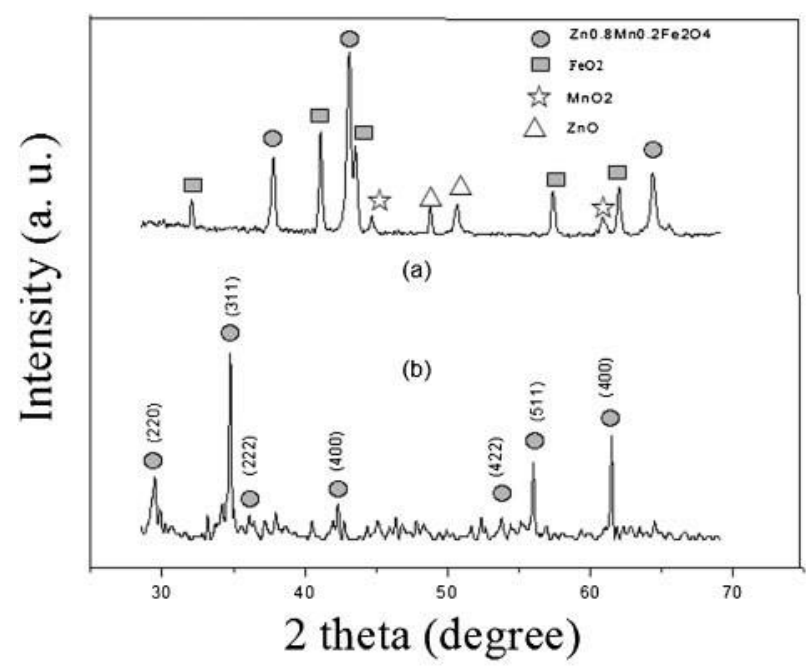

Fig. $2 X$-ray diffraction patterns of sample a before sintering and $b$ after sintering

Further with the heating rate to $100^{\circ} \mathrm{C} \mathrm{s}^{-1}$, it enables formation of a large quantity of adhesion and welding spots leading to produce more densified specimens.

Energy dispersive X-ray spectroscopy is used to study the components of sintered MnZn ferrites. The energy dispersive X-ray spectroscopy data for the centre area and area near the edge are presented in Table 1. The mass ratios of the sample are $\mathrm{Mn} / \mathrm{O}=0.53, \mathrm{Fe} / \mathrm{O}=2.04$ and $\mathrm{Zn} / \mathrm{O}=0.63$ at the centre area, and $\mathrm{Mn} / \mathrm{O}=0.64, \mathrm{Fe} / \mathrm{O}=2.50$ and $\mathrm{Zn} / \mathrm{O}=0.65$ in the area near the edge. The results indicate that there is componential segregation in the sintered $\mathrm{MnZn}$ ferrite materials.

\section{Densification behaviour}

As mentioned before, it requires long sintering time $(3-5 \mathrm{~h}$ ) and high sintering temperature (about $1250^{\circ} \mathrm{C}$ ) to complete densification process for conventional sintering technology. However, densification process could be accomplished at much lower temperature $\left(900^{\circ} \mathrm{C}\right)$ and shorter sintering time (4 min), which unambiguously demonstrates that densification mechanism of MnZn ferrite are different between multiphysical fields coupling sintering technology and conventional sintering method.

Variations of heating and shrinkage rates with heating time are shown in Fig. 4. It can be seen that the compact almost has no shrinkage in holding stage, suggesting that there is no formation of 
liquid phase in the compact. However, the appearance of sharp shrinkage rate appears in calefactive stage implies formation of a lot of liquid phases in the compact. These results indicate that densification process is significantly enhanced in calefactive stage, and maintaining process plays a negligible role in the densification of the compact.

Under the condition of electric field sintering, the relationship between the heating rate and the current through compact could be shown as below ${ }^{14}$

$$
\frac{I}{A}=\left(\frac{\rho C}{\sigma} \frac{\mathrm{d} T}{\mathrm{~d} t}\right)^{1 / 2}
$$

where I is the current passing through compact, A is the cross-sectional area of compact, $\mathrm{r}$ is the density of compact, $\mathrm{C}$ is the specific heat, $\mathrm{s}$ is the resistivity and $\mathrm{dT} / \mathrm{dt}$ is the heating rate.

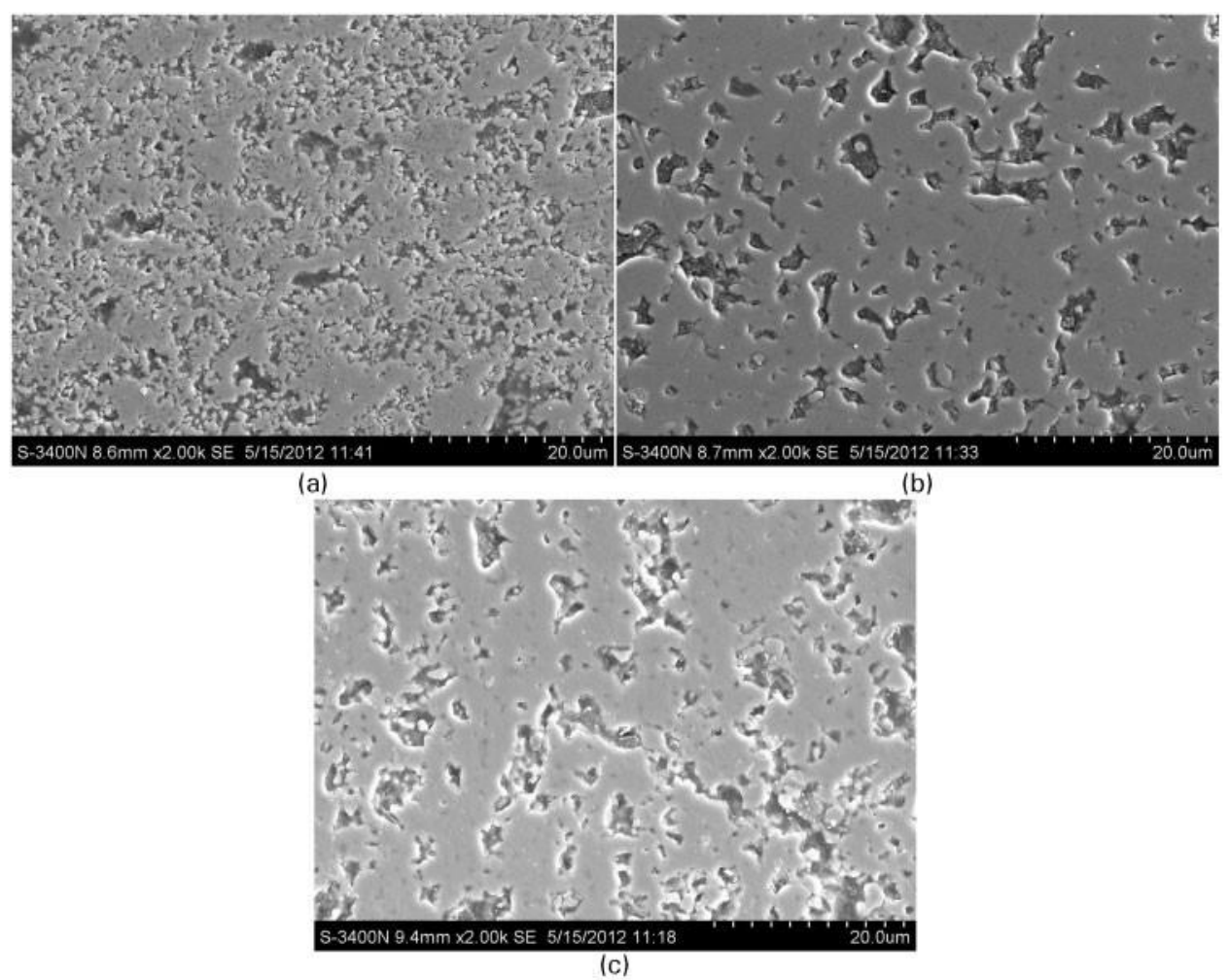

Fig. 3 Images (SEM) of MnZn ferrites sintered at $900^{\circ} \mathrm{C}$

From the above formula, it can be found that the current passing through the compact increases with the heating rate. According to Joule-Lenz's law, the Joule heat generated by the current passing through the graphite die could be given by

$$
Q=I^{2} R t
$$

where $\mathrm{Q}$ is the generated Joule heat when current passing through the compact, $\mathrm{R}$ is the resistance and $t$ is time.

The punches and die are heated by Joule heat generated by the current, and the powders are heated through heat transferred from the die and punches. As MnZn ferrites are non-conductive materials, electric current cannot go through the sintered sample, it deflects at the surface of the punch and then goes through the mould, at a certain moment. According to Ampere's law, 
electric current produces magnetic field, ${ }^{15}$ and the relationship between the magnetic field and the electric current could be shown as

$$
B=\mu_{\mathrm{i}} / 2 \pi \mathrm{h}
$$

where $\mathrm{h}$ is the distance between magnetic field and deflection current, and $\mathrm{i}$ is the current.

From the above formulas, it can be found that the current passing through the graphite die rapidly increases with heating rate, resulting in increased Joule heat and stronger magnetic field. Moreover, themagnetic field produced is alternating owning to the application of ac current, inducing the generation of electric field according to Maxwell's law of electromagnetic induction. Under the action of induced electric field, the typical phenomenon, i.e. field emission and electron bombardment, occurs in the punch. Especially, electron bombardment provides a substantial amount of heat for the MnZn ferrite16 and promotes solid phase reaction in the material. In addition, conductive cavity was formed between the punch and mould under the action of ac current, and the electron beam of field emission interacts with magnetic field, generating high frequency wave. ${ }^{17}$ MnZn ferrite absorbs the high frequency wave and thus provides indirect heating to the sample during sintering process, and microzone of high temperature was formed in the sample, which promotes.

\begin{tabular}{lcccc} 
Table 1 & \multicolumn{2}{c}{$\begin{array}{c}\text { Energy dispersive } \\
\text { centre area and area }\end{array}$ near edge of sample } \\
\hline & Mn/O & Fe/O & Zn/O & C/wt-\% \\
\hline Centre & 0.53 & 2.04 & 0.63 & $7 \cdot 27$ \\
Edge & 0.64 & 2.50 & 0.65 & 7.04 \\
\hline
\end{tabular}

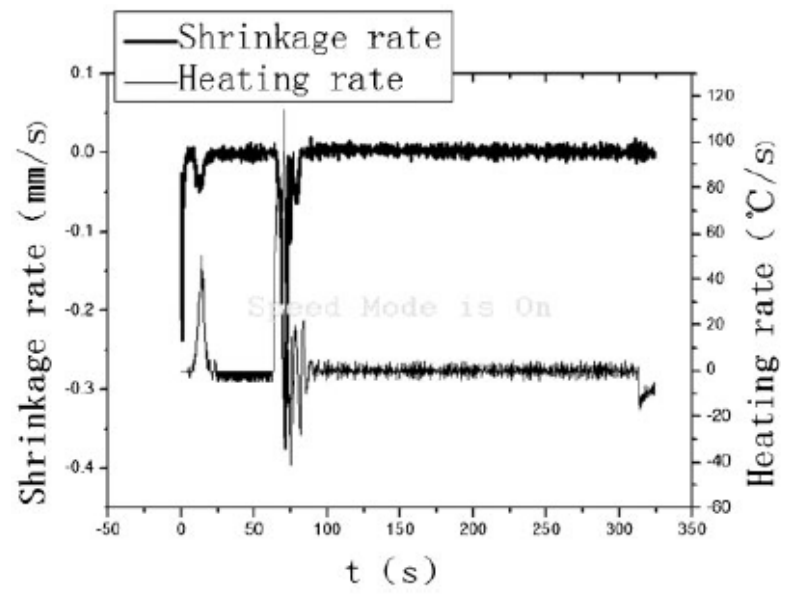

Fig. 4 Variations of shrinkage and heating rates with heating time of sample 


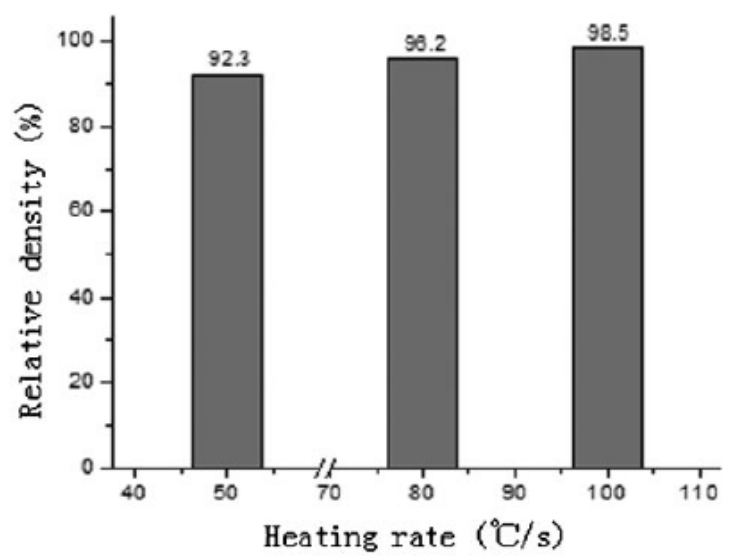

\section{Fig. 5 Relative density of compact sintered at $900^{\circ} \mathrm{C}$}

reaction of solid phase and formation of liquid phase. In all, these heating effects finally enhance the densification of MnZn ferrite process. It should be noted that $\mathrm{Mn}$ and Fe atoms deflect under the action of electromagnetic force, which results in composition segregation in the sintered sample.

\section{Density of specimens}

The densities of $\mathrm{Zn}_{0.8} \mathrm{Mn}_{0.2} \mathrm{Fe}_{2} \mathrm{O}_{4}$ (wt-\%) specimens sintered at heating rates ranging from 50 to $100^{\circ} \mathrm{C} \mathrm{s}^{-1}$ are shown in Fig. 5. It can be seen that relatively high densities (90-99\% of the theoretical value) are achieved for all the MnZn ferrites sintered under coupled multiphysical fields, and densities of the sintered specimens increase with the heating rates.

As mentioned in the section on 'Densification behaviour', both the current passing through the graphite die and the magnetic field rapidly increase with the heating rate, as well as the Joule heat. Consequently, the influence of the above factors efficiently enhanced the densification of $\mathrm{MnZn}$ ferrite.

\section{Magnetic properties}

In order to compare the multiphysical fields coupling sintering and conventional sintering, an MnZn ferrite sample with identical composition was sintered for $4 \mathrm{~h}$ at $1280^{\circ} \mathrm{C}$ by conventional protective atmosphere sintering, and the corresponding microstructure is shown in Fig. 6. Compared to Fig. 3, it can be found that although the sample sintered at much lower temperature $\left(900^{\circ} \mathrm{C}\right)$ and much shorter sintering time $(4 \mathrm{~min})$ (taking the $100^{\circ} \mathrm{C} \mathrm{s}^{-1}$ heated specimen as an example), the microstructures of both are almost same.

Table 2 lists the magnetic properties of MnZn ferrites sintered prepared by the two methods. It can be clearly found that the density of sample sintered under multiphysical fields coupling is 4.74 $\mathrm{g} \mathrm{cm}^{-3}$, which is the same as the density of conventional sintered sample. The maximum energy product of $\mathrm{MnZn}$ ferrite sintered under multiphysical fields coupling is 354.95Ez3 GOe. 


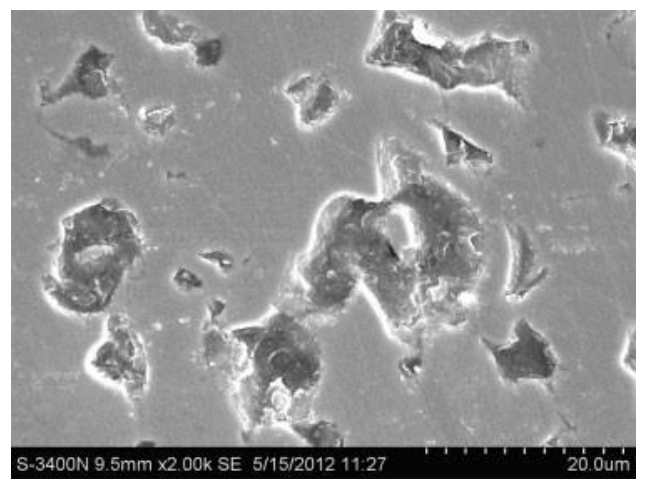

Fig. 6 Microstructure of conventional sintering of MnZn ferrite sintered for $4 \mathrm{~h}$ at $1280^{\circ} \mathrm{C}$

and $204.39 \%$ increase can be seen compared with conventional process. A slight increase in the remanences of the MnZn sample also can be achieved. However, the saturation magnetisation of sample sintered by multiphysical fields coupling method is $5.0050 \mathrm{emu} \mathrm{g}^{-1}$, while the saturation magnetisation of sample sintered by conventional method is $7.5522 \mathrm{emu} \mathrm{g}^{-1}$. The present results show that multiphysical fields coupling method could be an alternative way to prepare functional materials. Especially, when energy consumption and efficiency are considered, it holds distinctive advantages over SPS and conventional sintering methods.

Figure 7 shows the magnetic properties at $1 \mathrm{MHz}$ for $\mathrm{MnZn}$ ferrite sintered at $900^{\circ} \mathrm{C}$. As indicated in the above figures, the maximum energy product and saturation magnetisation of the $\mathrm{MnZn}$ ferrites increase with the heating rate for all cases, as well as the remanence and intrinsic coercive force when the heating rate is increased from 50 to $80^{\circ} \mathrm{C} \mathrm{s}^{-1}$. However, further increase of heating rate to $100^{\circ} \mathrm{C} \mathrm{s}^{-1}$ leads to substantial decrease in remanence and intrinsic coercive force.

\section{Conclusions}

From the work completed in this study, the following conclusions can be drawn.

1. Cylindrical bulk MnZn ferrites with diameters of $2.5 \mathrm{~mm}$, and heights of $2.5 \mathrm{~mm}$ were sintered by multiphysical fields coupling method. The discussion indicates that heating rate plays a critical role on the densification and the magnetic properties. Moreover, the maximum energy product and saturation magnetisation of the MnZn ferrites increase with the heating rate for all cases.

2. Some magnetic properties of MnZn ferrite sintered under multiphysical fields coupling are better than these obtained by conventional sintering, such as maximum energy product and remanence. In particular, a $204.39 \%$ increase in maximum energy product is obtained.

3. Densification mechanisms of multiphysical fields coupling sintering are different from these of conventional sintering. The electric field plays an important role in our proposed technology; apart from heat transferred from the die and punches, alternating magnetic field and high frequency wave play a critical role in the solid phase reaction and densification process. 
Table 2 Magnetic properties of MnZn ferrites obtained from different sintering methods

\begin{tabular}{llllll}
\hline & $\rho / \mathrm{g} \mathrm{cm}^{-3}$ & BH/GOe & Br/G & Hci/G & Ms/emu \\
\hline Multiphysical fields coupling sintering & 4.74 & $354 \cdot 95 \mathrm{E}+3$ & 7.0068 & 1.6177 & 5.0050 \\
Conventional sintering & 4.74 & $116.61 \mathrm{E}+3$ & 6.5790 & 0.2618 & 7.5522 \\
\hline
\end{tabular}
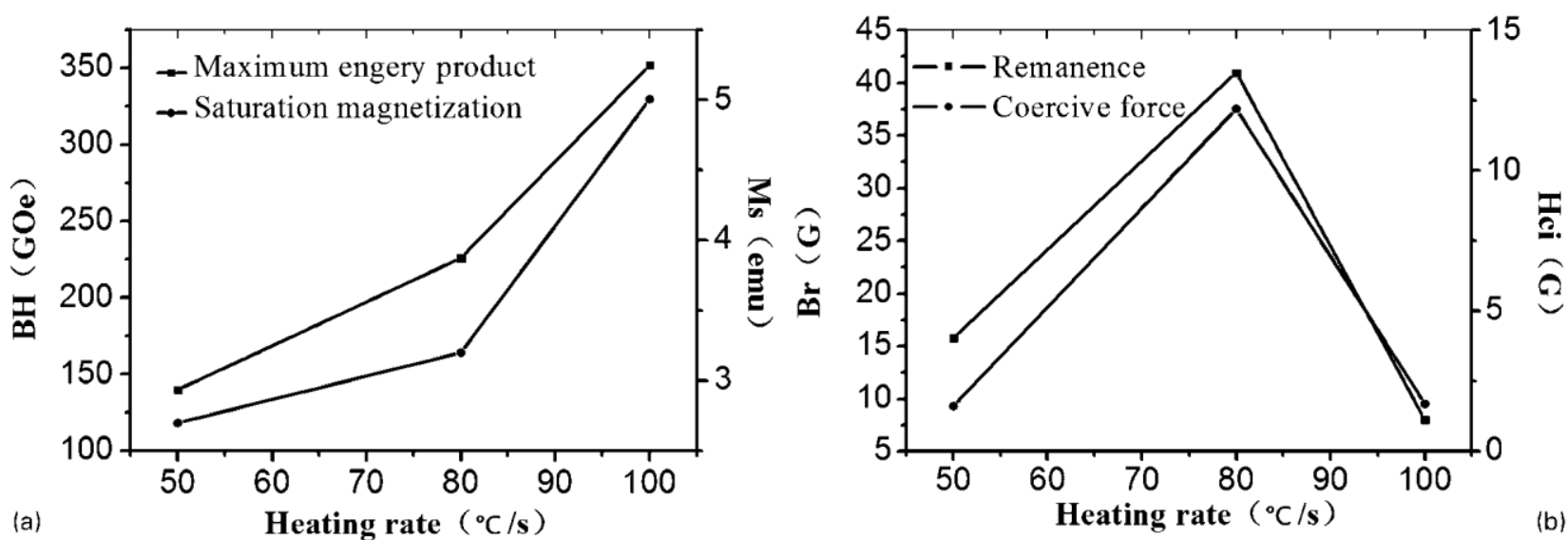

Fig. 7 Magnetic properties for MnZn ferrite sintered under multiphysical fields coupling at $900^{\circ} \mathrm{C}$

\section{Acknowledgements}

This research was supported by the National Nature Science Foundation of China (grant no. 51275322) and the UK Royal Society/China NSFC International Exchanges Programme (grant no. 51311130134) and the Research Foundation for the Young Teachers in the Sichuan University (grant no. 2012SCU11067)

\section{References}

[1]. Y. H. Guu, K. L. Tsai and L. K. Chen: 'An experimental study onelectrical discharge machining of manganese-zinc ferrite magnetic material', Mater. Manuf. Processes, 2007, 22, $66-70$.

[2]. P. M. Botta, P. G. Bercoff, E. F. Aglietti, H. R. Bertorello and J.M. Porto Lo'pez: 'Two alternative synthesis routes for MnZn ferrites using mechanochemical treatments', Ceram. Int., 2006, 32, 955-964.

[3]. Ch. Sujathaa, K. Venugopal Reddya, K. Sowri Babua, A.RamaChandra Reddya, K. H. Raob: 'Effect of sintering temperature on electromagnetic properties of NiCuZn ferrite', Ceram. Int., 2013, 39, 3077-3086.

[4]. E. DeFazio, P. G. Bercoff and S. E. Jacobo: 'Electromagneticproperties of manganese-zinc ferrite with lithium substitution', J. Magn. Magn. Mater., 2011, 323, 2813-2817.

[5]. K. Praveena, K. Sadhana and S. R. Murthy: 'Elastic behaviour ofmicrowave hydrothermally synthesized nanocrystalline $\mathrm{Mn}_{12 \mathrm{x}}-\mathrm{Zn}_{\mathrm{x}}$ ferrites', Mater. Res. Bull., 2012, 47, 1096-1103. 
[6]. G. Kogias, V. Tsakaloudi, P. VanderValk and V. Zaspalis: 'Improvement of the properties of MnZn ferrite power cores through improvements on the microstructure of the compacts', J. Magn. Magn. Mater., 2012, 324, 235-241.

[7]. J. Sun, J. Li, G. Sun and W. Qu: 'Synthesis of dense NiZn ferritesby spark plasma sintering', Ceram. Int., 2002, 28, 855-858.

[8]. J. Zhang, L. Yu, S. Yuan, S. Zhang and X. Zhao: 'Abnormalmorphology of nanocrystalline Mn-Zn ferrite sintered by pulse electric current sintering', J. Magn. Magn. Mater., 2009, 321, $3585-3588$.

[9]. G. Yang, Y. Yang, Y. Liu and M. Tu: 'Effect of sinteringtemperature on microstructure of NdFeB alloy sintered by an electric field', Rare Met. Mater. Eng., 2010, 39, 122-125.

[10]. N. Karakus, A. O. Kurt and H. O. Toplan: 'Production ofsinterable $\mathrm{Si}_{3} \mathrm{~N}_{4}$ from $\mathrm{SiO}_{2}-\mathrm{Li}_{2} \mathrm{O}-$ $\mathrm{Y}_{2} \mathrm{O}_{3}$ mixture', Mater. Manuf. Processes, 2012, 27, 797-801.

[11]. M. A. Kaya: 'Study on microstructure and fabrication of porousMg-10Al alloy', Mater. Manuf. Processes, 2012, 27, 605-608.

[12]. M. Ghobeiti Hasab, S. A. Seyyed Ebrahimi and A. Badiei: 'Theeffect of surfactant hydrocarbon tail length on the crystallite size of Sr-hexaferrite powders synthesized by a solgel auto-combustion method', J. Magn. Magn. Mater., 2007, 310, 2477-2479.

[13]. F. A. Deorsola and D. Vallauri: 'Densification of ultrafine WC-12Co cermets by pressure assisted fast electric sintering', Int. J. Refract. Met. Hard Mater., 2010, 28, 254-259.

[14]. W. Chen: 'Gleeble system and application', 1st edn; 1998, GleebleSystem School.

[15]. M. Pellizzari, M. Zadra and A. Fedrizzi: 'Development of a hybridtool produced by spark plasma sintering', Mater. Manuf. Processes, 2009, 24, 873-878.

[16]. E. C. Heeres, E. P. A. M Bakkers and A. L. Roest: 'Electronemission from individual indium arsenide semiconductor nanowires', Nano Lett., 2007, 7, 536-540.

[17]. S. Jin and D. Yin: 'Computational high frequency waves throughcurved interfaces via the Liouville equation and geometric theory of diffraction', J. Comput. Phys., 2008, 227, 61066139. 